\title{
Erratum
}

Journal of Microbiology (2021) Vol. 59, No. 10, pp. 898-910

DOI 10.1007/s12275-021-1235-0

\section{Brevibacterium limosum sp. nov., Brevibacterium pigmenatum sp. nov., and Brevibacterium atlanticum sp. nov., three novel dye decolorizing actinobacteria isolated from ocean sediments}

\author{
Shengxiang Pei ${ }^{1,2}$, Siwen Niu ${ }^{1}$, Fuquan Xie ${ }^{1}$, Wenjing Wang ${ }^{1}$, Shuang Zhang ${ }^{1}$, and Gaiyun Zhang ${ }^{1 *}$ \\ ${ }^{1}$ Key Laboratory of Marine Biogenetic Resources, Third Institute of Oceanography, Ministry of Natural Resources, Xiamen 361005, Fujian, P. R. China \\ ${ }^{2}$ State Key Laboratory of Marine Environmental Science, College of Ocean and EarthSciences, Xiamen University, Xiamen 361102, Fujian, P. R. China
}

In the article by Pei et al. published in Journal of Microbiology 2021; 59, 898-910,

the name Brevibacterium pigmenatum should be corrected to Brevibacterium pigmentatum in the title of the paper, abstract, keywords, introduction, protologue, Figures, and Supplementary data in the article.

The title for this article should have read:

Brevibacterium limosum sp. nov., Brevibacterium pigmentatum sp. nov., and Brevibacterium atlanticum sp. nov., three novel dye decolorizing actinobacteria isolated from ocean sediments

The keywords should have read:

Keywords: Brevibacterium limosum sp. nov., Brevibacterium pigmentatum sp. nov., Brevibacterium atlanticum sp. nov., genomic analysis, dye decolorization

The last sentence of Abstract for this article should have read:

Based on the phylogenetic, genotypic and phenotypic data, strains $02^{\mathrm{T}}, \mathrm{YB}_{2} 35^{\mathrm{T}}$ and $\mathrm{WO} 024^{\mathrm{T}}$ clearly represent three novel taxa within the genus Brevibacterium, for which the names Brevibacterium limosum sp. nov. (type strain o2 ${ }^{\mathrm{T}}=\mathrm{JCM} 33844^{\mathrm{T}}$ $=$ MCCC 1A09961 $\left.{ }^{\mathrm{T}}\right)$, Brevibacterium pigmentatum sp. nov. (type strain YB235 $\left.{ }^{\mathrm{T}}=\mathrm{JCM} 33843^{\mathrm{T}}=\mathrm{MCCC} 1 \mathrm{~A} 09842^{\mathrm{T}}\right)$ and Brevibacterium atlanticum sp. nov. (type strain $\left.\mathrm{WO}_{0} 4^{\mathrm{T}}=\mathrm{JCM} 33846^{\mathrm{T}}=\mathrm{MCCC} 1 \mathrm{~A} 16743^{\mathrm{T}}\right)$ are proposed.

The last sentence of Introduction should have read:

Through polyphasic taxonomic analysis, strains $\mathrm{YB}_{2} 35^{\mathrm{T}}$, WO $024^{\mathrm{T}}$, and $02^{\mathrm{T}}$ were identified as three novel dye decolorizing bacterial species, for which the names Brevibacterium pigmentatum, Brevibacterium atlanticum, and Brevibacterium limosum are proposed.

The protologue should have read:

Description of Brevibacterium pigmentatum sp. nov.

Brevibacterium pigmentatum (pig.men.ta'tum. L. neut. adj. pigmentatum pigmented).

Cells are Gram-stain positive, aerobic, non-spore-forming, non-motile and long rod-shaped (approximately $0.2-0.5 \mu \mathrm{m} \times$ $1.5-4.0 \mu \mathrm{m}$ in size) after incubation for 3 days at $30^{\circ} \mathrm{C}$ on MA. Colonies are light orange color, opacity, smooth, moist, low convex with middle margins. Growth well on MA, LB and TSA plates, and moderate growth on ISP 4 and ISP 2 plates. Diffusible pigment is produced at MA medium. Growth is observed at $4-45^{\circ} \mathrm{C}, \mathrm{pH} 6.0-10.0$ and in the presence of $0-20 \%$ (w/v) NaCl. Optimum growth occurs at $30-37^{\circ} \mathrm{C}, \mathrm{pH} 7.0$, and in 3-5\% (w/v) NaCl. Oxidase- and catalase- positive. Positive for gelatin hydrolysis and the activities of pyrazinamidase and alkaline phosphatase; negative for nitrate reduction, esculin hydrolysis and the activities of urease, pyrrolidone peptidase, $\beta$-glucuronidase, $\beta$-galactosidase, $\alpha$-glucosidase and $N$-acetyl- $\beta$-glucosaminidase. Acid is produced from D-glucose, D-ribose, D-xylose, D-malic acid and D-lactose, But not from D-mannitol, D-lactose and D-saccharose. The principal fatty acids were anteiso- $\mathrm{C}_{17: 0}$ and anteiso- $\mathrm{C}_{15: 0}$. The major polar lipids were diphosphatidylglycerol, phosphatidylglycerol and one unknown glycolipid. The diagnostic diamino acid in the cell-wall peptidoglycan is meso- diaminopimelic acid. The predominant menaquinone was determined to be menaquinone MK- $8\left(\mathrm{H}_{2}\right)$. The DNA G + C base composition is $64.6 \mathrm{~mol} \%$ and the genome size is $3.91 \mathrm{Mb}$. The type strain, $\mathrm{YB}_{235^{\mathrm{T}}}(=\mathrm{JCM}$ $33843^{\mathrm{T}}=$ MCCC $1 \mathrm{~A} 09842^{\mathrm{T}}$ ) was isolated from an ocean sediment of the South Atlantic. 
The Figures should have shown:

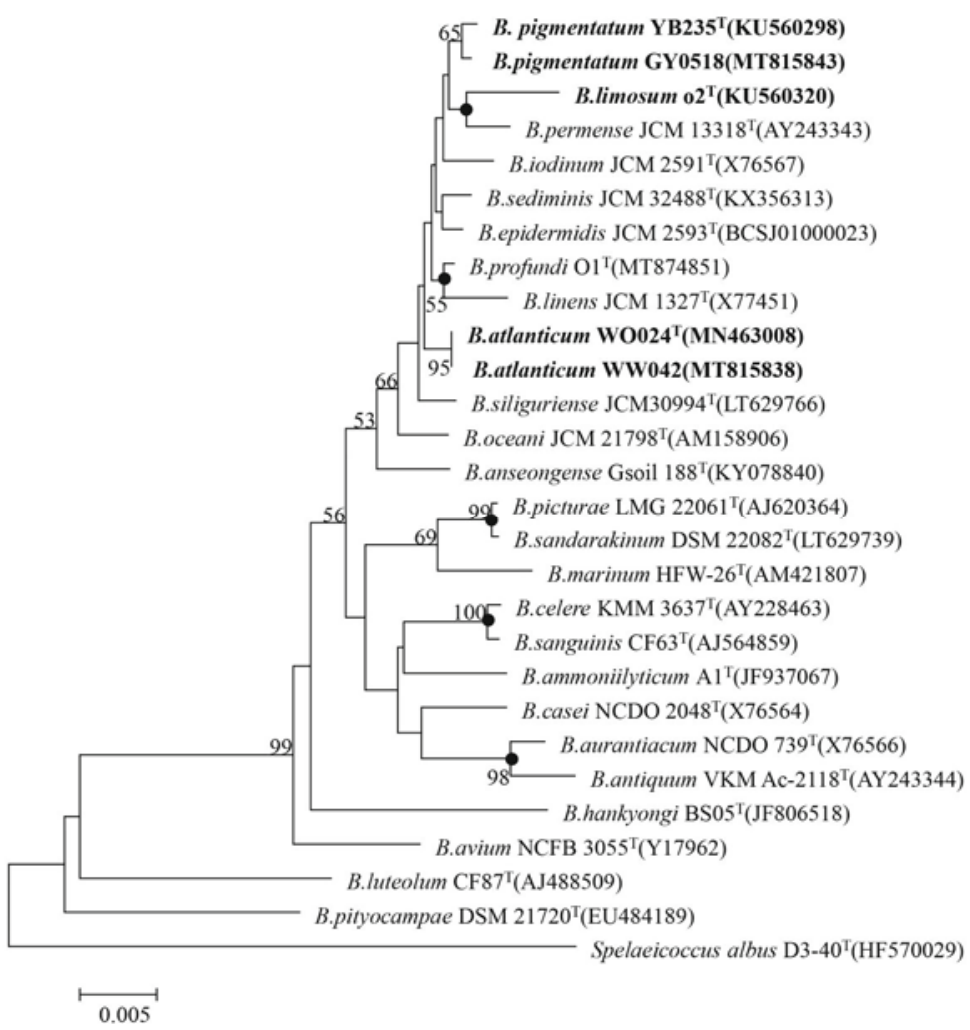

Fig. 1.

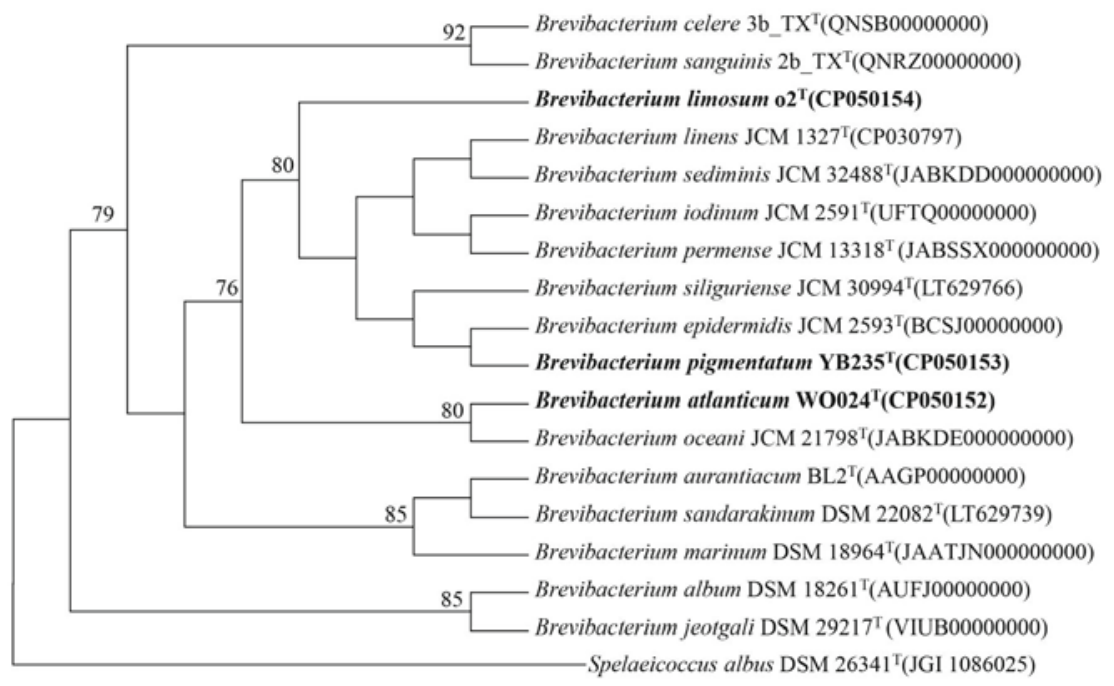

Fig. 3.

The Supplementary data should have shown as the enclosed file.

The authors apologize for any inconvenience that this may have caused. 